EXTENDED REPORT

\title{
Determinants of direct costs in Dutch rheumatoid arthritis patients
}

\section{S M M Verstappen, H Verkleii, J W J Biilsma, E Buskens, A A Kruize, A H M Heurkens, M J van der Veen, J W G Jacobs, on behalf of the Utrecht Rheumatoid Arthritis Cohort Study group (SRU)}

Ann Rheum Dis 2004;63:817-824. doi: 10.1136/ard.2003.014340
See end of article for authors' affiliations

Correspondence to: Dr S M M Verstappen, University Medical Center Utrecht, Department of Rheumatology \& Clinical Immunology, F02.127,

PO Box 85500, 3508 GA Utrecht, The Netherlands; s.verstappen@azu.nl

Accepted

9 December 2003
Objectives: To estimate annual direct costs in four distinct disease duration groups $(0$ to $\leqslant 2,2$ to $\leqslant 6,6$ to $\leqslant 10$, and $>10$ years) of patients with rheumatoid arthritis (RA), to determine predictors of high costs and to describe characteristics of patients with high and with low costs.

Methods: A questionnaire assessing RA related care and resource utilisation rates and costs was completed by 615 RA patients. Predictive variables for incurred costs, as observed during the first year after disease onset, were determined in a subgroup of patients $(n=347)$.

Results: Mean (median) annual direct costs for the four groups with increasing disease duration were respectively: $€ 5235$ (2923), $€ 3930$ (1968), $€ 4664$ (1952), and $€ 8243$ (3778), ( $<0.05)$. During the first 2 years of the disease total direct costs comprised mainly of consultations with heatlhcare workers (28\%). After 10 years, devices and adaptations were the main contributors $(40 \%)$ to total costs. Positive rheumatoid factor results at the time of diagnosis and deterioration of functional disability in the first year of disease were predictors of high costs later on in the course of the disease.

Conclusion: Annual direct costs among patients with a disease duration of less than 2 years tend to be lower among patients with a disease duration of between 2 and 10 years than among patients with a disease duration of more than 10 years. In addition, the proportional distribution of different cost categories to total costs increases with with increasing disease duration.
C ost of illness (COI) studies provide insight into the expenses associated with chronic diseases such as healthcare budgets and for pharmaceutical companies to evaluate cost effectiveness of new drugs. COI studies consist of three types of cost: direct, indirect, and intangible. ${ }^{1}$ In a review article, ${ }^{2}$ mean direct costs, pooled from several studies, were estimated to be $\$ 5720$ per RA patient per year in 1996. Indirect costs averaged $\$ 5822$ per patient per year. Disease duration in the studies reviewed ranged from 0 to 21 years. However, large differences in distribution of total direct costs were observed between the reported studies. This might partly be explained by an inadequate definition of different cost categories and the use of different sources to estimate total costs among the studies. The inconclusive results led the authors to suggest that future studies should: (a) report direct and indirect costs separately; $(b)$ identify the different components of direct costs; (c) specify data sources and unit costs, thus allowing the estimates to be checked for different heatlhcare systems; and $(d)$ perform sensitivity analyses. ${ }^{2}$

Regardless of differences in methods and results, all studies concluded that the observed short and long term costs for RA impose a burden on individual RA patients, health services, and society. Preferably, predictors of RA related costs over the course of the disease should be identified in economic studies. These predictive factors would allow adequate resource allocation and may encourage research efforts to potentially prevent disease progression and thus high expenses. Few studies have identified such predictors. In a previous study, ${ }^{3}$ fewer years of education, low employment status, low global wellbeing, and high functional disability (as rated by the Health Assessment Questionnaire; HAQ) predicted high total direct costs Regrettably, in this study several clinical and psychological features were not available for analysis. In a number of cross sectional studies, serious functional disability, ${ }^{45}$ lower wellbeing, ${ }^{6}$ and low global health ${ }^{7}$ appeared to be associated with high costs.

The aim of this study was to estimate total annual direct costs in distinct disease duration groups among Dutch patients with rheumatoid arthritis, and to determine which sociodemographic, clinical, and psychological variables were associated with high direct costs. In addition, variables measured at baseline and during the first year after disease onset were evaluated with respect to their prediction of direct costs at a later stage in the course of the disease.

\section{PATIENTS AND METHODS}

\section{Patients}

Patients attending one of the seven rheumatology outpatient clinics in the region of Utrecht, collaborating in the Utrecht Rheumatoid Arthritis Cohort study group, were asked to participate in this COI study. These patients had either been included in one of the two inception cohorts studies carried out by the Utrecht Rheumatoid Arthritis Cohort study group or were consecutive outpatients with longstanding RA. The first inception cohort started in 1990 and early RA patients (disease duration $<1$ year) were randomly assigned to one of four therapeutic regimens: pyramid, intramuscular gold, methotrexate, or hydroxychloroquine. ${ }^{8} 9$ Clinical variables of these patients were assessed at baseline and every 3 months during the first 2 years, and thereafter every 6 months. Of the 709 patients originally included in this first cohort, 517 patients who were still included were asked to participate in the present COI study.

Abbreviations: AUC, area under the curve; $\mathrm{COI}$, cost of illness; ESR, erythrocyte sedimentation rate; $\mathrm{HAQ}$, Health Assessment Questionnaire; IRGL, Impact of Rheumatic Diseases on Health and Lifestyle; RA, rheumatoid arthritis 
The second inception cohort in early RA patients (disease duration $<1$ year) started in 1998. Patients were randomly allocated to one of the two methotrexate regimens: intensive treatment $v$ conventional treatment, both with methotrexate (starting dosage methotrexate $7.5 \mathrm{mg} /$ week increased stepwise to $30 \mathrm{mg} /$ week if needed, depending on individual disease activity). During the first 2 years, patients in the intensive treatment group attended the outpatient clinic once every month, and patients in the conventional treatment group attended once every 3 months. Treatment was tailored to the individual patient, but in the intensive treatment group the dosage of methotrexate was increased more rapidly than in the conventional treatment group. Clinical data on these patients were assessed at study onset and at each visit. All 94 included patients of this cohort were asked to participate in the present COI study. Patients of both inception cohorts fulfilled the 1987 American College of Rheumatology criteria $^{10}$ for RA.

In addition, to assure a representative sample of patients with RA at all stages of the disease, consecutive outpatients with a disease duration of more than 10 years attending one of the seven outpatient clinics of the Utrecht Rheumatoid Arthritis Cohort study group were invited to participate in the present study $(n=127)$. At this visit, clinical examination was performed and date of disease onset was obtained from medical records.

\section{Estimating direct costs}

A questionnaire comprising self reported questions regarding care and resource utilisation in relation to RA was sent out to all 738 RA patients. The questionnaire also included the EuroQol (EQ-D5 $)^{11}$ and questions on sociodemographic characteristics. To adjust for possible seasonal influences, half of the patients received the questionnaire in October 1999 and the other half in April 2000. All costs were calculated from a societal perspective-that is, they represent an estimate of the actual resources used on the care of RA, not just those incurred by a payer, healthcare professional, institution, or individual with RA. Total direct costs were computed as the sum of costs for the following predefined categories: (a) consultations with healthcare workers; (b) admissions to healthcare facilities (hospital including surgical procedures, rehabilitation centre, and nursing home); (c) medication; (d) laboratory tests; (e) devices needed to perform daily activities and adaptations in and around the house; $(f)$ alternative medicines; and $(g)$ extra costs. Except for patients' lost time, all categories were similar to those items of healthcare costs and other disease related costs as recommended for COI studies on direct costs. $^{12}$ Direct medical costs incurred per patient were estimated by multiplying volumes by costs per unit.

\section{Reported volumes and costs}

Patients were asked to the report number of contacts, costs, or utilisation rates in the previous 3 months for the following categories: number of consultations with healthcare workers, costs for alternative therapies, and extra costs (such as transportation, additional energy expenditures, maintenance in and around the house). Volumes and costs were multiplied by 4 to estimate annual resource utilisation rates and annual costs. In addition, patients were asked to report rates or costs in the past year of the following items: number of days spent in (a) a hospital (including surgical procedures), (b) a rehabilitation centre, and/or (c) a nursing home; purchase of adaptations in/around the house; and devices needed to perform activities of daily living. For medication, patients were asked to specify the type and dosage of RA related drugs used at time of completing the questionnaire. If patients mentioned using one of the cost categories above, but did not report rates or costs, mean rates or costs as reported by other patients pertaining to that specific item were used.

\section{Unit prices}

The following established methods were used to assign unit prices to the different items within each category. For days spent in care facilities, consultations with heatlhcare professionals, and travel expenses, we used costs derived from Methods and Guidelines for Economic Evaluations in Health Care (Dutch Guidelines for Pharmaco-economic COI Studies; see Appendix for unit prices). ${ }^{13}$ For admissions to the hospital and for outpatient visits to specialists, a distinction between peripheral and university hospitals was made. For costs of medication, the official drug price was used to calculate the unit cost for each drug. In case of multiple prices (for example, generic drugs), the lowest drug price was used. In addition, for each prescribed drug an additional fee of $€ 21$ per year for pharmaceutical administration was added to the drug price. ${ }^{13}$ Estimates of costs of various surgical procedures and laboratory tests were derived from the Dutch College for Rates in Health Care Guidelines. ${ }^{14}$ For costs of adaptations and devices, extra costs, and costs of alternative medicines, patients' self reported costs were used. Costs for laboratory tests included costs for monitoring for side effects of different disease modifying anti-rheumatic drugs according to schedules used in the University Medical Center, Utrecht, and costs for routine RA related laboratory tests. In cases with at least one consultation with a rheumatologist, cost of an $x$ ray of the hands and feet per year was included in total laboratory costs.

\section{Statistical analyses}

The first objective of this study was to describe total direct costs among four groups of patients with distinct disease duration ( 0 to $\leqslant 2,2$ to $\leqslant 6,6$ to $\leqslant 10,>10$ years). Because data were highly skewed, median (mean) (SD) annual costs and utilisation rates of these groups were estimated and compared using the Kruskall-Wallis test $(\mathrm{p}<0.05)$.

\section{High $v$ low costs, a cross-sectional analysis}

In each disease duration group, demographic, clinical, and psychological variables (obtained from another questionnaire, the Impact of Rheumatic Diseases on Health and Lifestyle questionnaire (IRGL) ${ }^{15}$ ), as assessed during the year this COI study was conducted, were compared between patients with high costs $v$ those with low costs. Median costs were used as the cutoff point to divide patients into the low or high cost group. Firstly, contribution of each variable was tested univariately using the $\chi^{2}$ test for categorical data, and the Mann-Whitney $U$ test or unpaired two tailed $t$ test for continuous data, where appropriate. In a second analysis, a multiple logistic regression model was constructed to evaluate the association between multiple sociodemographic characteristics, clinical variables, disease duration, and psychological variables (independent variables) and total costs as dependent variable (high $v$ low costs). The model was built using a stepwise procedure and variables were included when $\mathrm{p}<0.05$.

\section{Prognostic factors, a longitudinal analysis}

For this analysis, only data on patients included in the first inception cohort were used. A forward linear regression analysis was performed to determine whether specific baseline demographic, clinical, and psychological variables measured during the first year after disease onset predict (high) costs later on in the course of the disease. Because the distribution of total costs was highly skewed, we used the natural log transformation for total direct costs as dependent variable. For continuous clinical variables, except for 
radiological damage, and for all items of the IRGL questionnaire we determined the delta area under the curve (AUC) standardised by time ( 12 months). This delta AUC is a summary measure that integrates serial changes from baseline. ${ }^{16}{ }^{17}$ To calculate the delta AUC, we inferred missing values by the mean value of the previous and the following score. Radiographic damage was included as change from baseline over the first year. Complete baseline and first year data were available for 347 patients. Except for gender, no statistically significant differences were found when comparing demographic and clinical variables of these patients with those of the excluded patients.

Firstly, all variables were tested univariately and then entered in the full model applying forward selection-that is, in order of statistical significance: rheumatoid factor at baseline (negative/positive); change in radiological damage over the first year; IRGL item "mobility"; functional disability (HAQ); Thompson joint score; gender; IRGL item "self care"; ESR; visual analogue scale (VAS) item "general wellbeing"; IRGL item "depressed mood"; morning stiffness; IRGL item "cheerful mood"; IRGL item "pain"; IRGL item "anxiety"; disease duration; age at onset RA; and VAS item "pain". In a second analysis, all items from the IRGL questionnaire were excluded to reduce the number of independent variables.

\section{RESULTS}

\section{Patients}

Of the 738 RA patients who received a self report questionnaire, 632 questionnaires $(86 \%)$ were returned. In 17 cases, the data were incomplete, leaving data on 615 patients for this COI study on direct costs. Table l shows the demographic characteristics, disease activity (VAS), functional disability (HAQ), QoL, and number of co-morbidities for each of the four disease duration groups. Of the the 615 patients, 73\% was female, mean (SD) age was 60 (14) years, and disease duration 7.1 (7.0) years. Median scores for functional disability (HAQ), VAS disease activity, and QoL were significantly different between the four disease duration groups. In addition, number of co-morbidities was different between the four groups. The most frequently encountered co-morbidity was cardiovascular disease (44\%).

\section{Estimation of costs}

Median annual direct (mean) (SD) costs in euros for each of the four groups of patients with increasing disease duration, respectively, were as follows: €2923 (€5235) (€9697), €1967 (€3930) (€6737), €1952 (€4664) (€10940), and €3778 (€8243) $(€ 11850) \quad(p<0.001)$. Annual direct costs of all $615 \mathrm{RA}$ patients averaged €5058 (€9463) (range €0-124 614) per patient per year. Direct costs for different predefined categories among the four groups separately, and for the total study population are shown in table 2. Median costs for various categories, except for costs of alternative medicines, differed significantly between the four disease duration groups.

Admissions to care facilities accounted for $27 \%$ (disease duration $0-2$ years) and $24 \%$ (disease duration $>10$ years) of total direct costs, even though only $9(9 \%)$ and $23(22 \%)$ of the patients, respectively, were hospitalised or admitted to a rehabilitation centre (fig 1 ). Of the 21 patients hospitalised in the group of patients with a disease duration $>10$ years, 13 $(62 \%)$ underwent surgery. The total study population spent a mean (SD) 1.5 (6.1) days (range 0-64) in the hospital per year, and 1.4 (13.0) days (range 0-180) in a rehabilitation centre per year. None of the patients was admitted to a nursing home. Mean (SD) hospitalisation costs were €391 (€1602) per patient per year. In addition, surgical procedures added an extra mean of €152 (€2222) to total hospital costs. As depicted in table 2, no patients underwent surgery in the first 2 years of disease. Patients with longstanding disease spent on average 3.4 (21) days in a rehabilitation centre, accounting for $€ 971$ per patient per year.

For patients with a disease duration of more than 2 years, costs for purchase of devices and/or adaptations comprised the largest component of RA related costs, ranging between $34 \%$ and $44 \%$ of total direct costs across the three disease duration groups. In the group of patients with longstanding RA, major adaptations such as adjustments to kitchens and cars were the predominant contributers to these high costs.

\begin{tabular}{|c|c|c|c|c|c|}
\hline & \multicolumn{4}{|c|}{ Disease duration, years } & \multirow[b]{2}{*}{$\begin{array}{l}\text { All } \\
(n=615)\end{array}$} \\
\hline & $\begin{array}{l}0 \text { to } \leqslant 2 \\
(n=96)\end{array}$ & $\begin{array}{l}2 \text { to } \leqslant 6 \\
(n=261)\end{array}$ & $\begin{array}{l}6 \text { to } \leq 10 \\
(n=152)\end{array}$ & $\begin{array}{l}\geqslant 10 \\
(n=1060)\end{array}$ & \\
\hline Age, years & $54(15)$ & $60(14)$ & $63(13)$ & $62(12)$ & $60(14)$ \\
\hline Sex, female & $70(73 \%)$ & $192(74 \%)$ & $102(67 \%)$ & $85(80 \%)$ & $450(73 \%)$ \\
\hline Disease duration, years & $0.9(0.6)$ & $0.4(1.2)$ & $7.8(1.1)$ & $19.4(8.2)$ & $7.1(7.0)$ \\
\hline VAS rheumatoid arthritis, $\mathrm{mm}^{*}$ & $67(24)$ & $62(25)$ & $60(25)$ & $50(23)$ & $60(25)$ \\
\hline Functional disability, $\mathrm{HAQ}^{*}$ & $1.1(0.7)$ & $1.0(0.70)$ & $1.2(0.8)$ & $1.6(0.8)$ & $1.2(0.8)$ \\
\hline Quality of life, EuroQol* & $0.6(0.3)$ & $0.7(0.20)$ & $0.7(0.2)$ & $0.5(0.3)$ & $0.6(0.3)$ \\
\hline \multicolumn{6}{|l|}{ Marital status } \\
\hline Married & $62(65 \%)$ & 193 (74\%) & $103(68 \%)$ & $69(65 \%)$ & $427(69 \%)$ \\
\hline Unmarried & $14(15 \%)$ & $18(7 \%)$ & $14(9 \%)$ & $8(8 \%)$ & $54(9 \%)$ \\
\hline Divorced & $10(10 \%)$ & $19(7 \%)$ & $7(5 \%)$ & $9(9 \%)$ & $45(7 \%)$ \\
\hline Widowed & $10(10 \%)$ & $26(10 \%)$ & $27(18 \%)$ & $19(18 \%)$ & $82(13 \%)$ \\
\hline \multicolumn{6}{|l|}{ Education: } \\
\hline $\begin{array}{l}\text { Low: < high vocational/ } \\
\text { university }\end{array}$ & $83(86 \%)$ & $216(83 \%)$ & $135(89 \%)$ & 97 (92\%) & $531(86 \%)$ \\
\hline $\begin{array}{l}\text { High: } \geqslant \text { high vocational/ } \\
\text { university }\end{array}$ & $13(14 \%)$ & $36(14 \%)$ & $16(11 \%)$ & $7(7 \%)$ & $72(12 \%)$ \\
\hline$\geqslant 1$ co-morbidity * & 40 (42\%) & $128(49 \%)$ & $93(61 \%)$ & $65(61 \%)$ & $326(53 \%)$ \\
\hline
\end{tabular}

*Statistically significantly different $(p<0.01)$.

Scores are mean values (SD) or number of patients $(\%)$.

VAS rheumatoid arthritis ( 0 to $100 \mathrm{~mm}=$ best score); $\mathrm{HAQ}$, functional disability score (0 to $3=$ worst score); EuroQol, quality of life $(-0.594$ to $1.0=$ best health status).

Sum of patients for the categories marital status and education may not be equal to total number of patients because of missing data. 
Table 2 Costs in euros as estimated for each of the seven predefined categories, separately. Costs are summarised for four groups of patients with increasing disease duration and for the total study group

\begin{tabular}{|c|c|c|c|c|c|}
\hline \multirow[b]{2}{*}{ Cost categories } & \multicolumn{4}{|c|}{ Disease duration, years } & \multirow[b]{2}{*}{ All $(n=615)$} \\
\hline & 0 to $\leqslant 2(n=96)$ & 2 to $\leqslant 6(n=261)$ & 6 to $\leqslant 10(n=152)$ & $\geqslant 10(n=1060)$ & \\
\hline Heathcare workers* & $\begin{array}{l}1448(1433) \\
(0-8090)\end{array}$ & $\begin{array}{l}825(1250) \\
(0-1348)\end{array}$ & $\begin{array}{l}1002(1986) \\
(0-16643)\end{array}$ & $\begin{array}{l}1262(1443) \\
(163-6715)\end{array}$ & $\begin{array}{l}1041(1536) \\
(0-16643)\end{array}$ \\
\hline Admissions to care & 1391 (7283) & $665(4560)$ & $440(1675)$ & 1943 (8293) & $943(5456)$ \\
\hline facilities* & $(0-57930)$ & $(0-62414)$ & $(0-12248)$ & $(0-63077)$ & $(0-63077)$ \\
\hline Total hospital costs & $376(1348)$ & 505 (4083) & $414(1512)$ & $972(2880)$ & $543(3060)$ \\
\hline Hospitalisation & 376 (1348) & 260 (1385) & $358(1376)$ & 775 (2387) & 391 (1602) \\
\hline Surgery & 0 & $246(3378)$ & $55(262)$ & $197(686)$ & $152(2222)$ \\
\hline Rehabilitation centre & 1015 (6383) & $159(1490)$ & $26(324)$ & $971(6044)$ & $390(3700)$ \\
\hline RA related medication* & $\begin{array}{l}478(406) \\
(0-2895)\end{array}$ & $\begin{array}{l}505(821) \\
(0-11364)\end{array}$ & $\begin{array}{l}509(674) \\
(0-5851)\end{array}$ & $\begin{array}{l}847(1669) \\
(0-12513)\end{array}$ & $\begin{array}{l}561(957) \\
(0-12513)\end{array}$ \\
\hline Devices and & $963(2247)$ & 1345 (3544) & $2051(9280)$ & $3259(6493)$ & $1790(5922)$ \\
\hline adaptations* & $(0-15571)$ & $(0-25679)$ & $(0-110269)$ & $(0-31895)$ & $(0-110268)$ \\
\hline \multirow[t]{2}{*}{ Laboratory tests* } & $296(131)$ & $226(144)$ & 222 (169) & $253(88)$ & $241(143)$ \\
\hline & $(75-975)$ & $(0-1682)$ & $(0-1144)$ & $(75-564)$ & $(0-1683)$ \\
\hline \multirow[t]{2}{*}{ Alternative therapies } & $103(338)$ & $42(241)$ & 79 (382) & $20(118)$ & $57(285)$ \\
\hline & $(0-1815)$ & (0-2722) & $(0-3186)$ & $(0-938)$ & $(0-3186)$ \\
\hline \multirow[t]{2}{*}{ Total extra costs* } & $554(1094)$ & $322(995)$ & 361 (751) & 659 (1617) & $426(1099)$ \\
\hline & $(0-6080)$ & $(0-12880)$ & $(0-4299)$ & $(0-13770)$ & $(0-13770)$ \\
\hline $\begin{array}{l}\text { Additional energy } \\
\text { costs }\end{array}$ & $42(111)$ & $30(91)$ & $32(110)$ & $48(126)$ & $35(105)$ \\
\hline Diet & $20(87)$ & 0 & $16(82)$ & $14(65)$ & $10(60)$ \\
\hline $\begin{array}{l}\text { Over the counter } \\
\text { medication }\end{array}$ & $13(49)$ & $13(58)$ & $13(75)$ & $14(46)$ & $13(60)$ \\
\hline Homeopathy & $72(276)$ & $33(214)$ & $15(105)$ & $16(59)$ & 32 (187) \\
\hline Health food & 12 (101) & $5(37)$ & $2(16)$ & 0 & $5(47)$ \\
\hline $\begin{array}{l}\text { Payments to friends } \\
\text { for help }\end{array}$ & $15(61)$ & $27(120)$ & $15(72)$ & $40(162)$ & $24(112)$ \\
\hline $\begin{array}{l}\text { Maintenance in and } \\
\text { around the house }\end{array}$ & $153(570)$ & 69 (342) & $104(434)$ & 129 (393) & $101(417)$ \\
\hline Clothing & $51(301)$ & $21(124)$ & $36(243)$ & $9(69)$ & 27 (190) \\
\hline Telephone & $26(102)$ & $8(37)$ & $9(38)$ & 31 (87) & $15(63)$ \\
\hline Parking permit & $2(130$ & $5(27)$ & $15(85)$ & $25(136)$ & $10(73)$ \\
\hline Transportation & $126(345)$ & $57(205)$ & $75(281)$ & $138(342)$ & 86 (277) \\
\hline Remaining costs & 0 & $53(787)$ & 19 (143) & $85(530)$ & 42 (562) \\
\hline Mean (median) (range) & $5235(2923)$ & 3930 (1968) & 4664 (1952) & $8243(3778)$ & $5058(2247)$ \\
\hline total direct costs * & $(570-74080)$ & $(0-67236)$ & $(0-124614)$ & $(363-73626)$ & $(0-124614)$ \\
\hline
\end{tabular}

Costs are mean (SD) or mean (SD) (range) unless otherwise stated.

*Significantly different across the four disease duration groups.

In the year prior to completing the questionnaire, 396 (64\%) patients needed at least one device or adaptation (average costs €2780 (7194) (range €5-110 269). Specially adapted taps were required by many patients $(22 \%)$, and $21 \%$ of the total study population would like to have additional adaptations. Additional wanted adaptations were: orthopaedic (20 patients), mobility (29 patients), bathroom (63 patients), kitchen (53 patients), and for commuting to work (30 patients).

Medication accounted for $11 \%$ (mean) (SD) (€561) (957) of total costs for the whole study population. This percentage was approximately equal for the four disease duration groups. Most patients (93\%) were receiving at least one RA related drug at the time of completing the questionnaire. This study was performed just before anti-TNF- $\alpha$ medication became widely available in daily clinical practise in the Netherlands. Only three patients received these agents, estimated to cost €11 345 per patient per year. Annual costs for laboratory tests could be divided into costs for monitoring of side effects (mean €97) and costs for routine laboratory tests for RA such as erythrocyte sedimentation rate (ESR) (mean €144) among all patients.

Table 2 also shows the distribution of extra costs, of which maintenance in and around the house contributed most to total extra costs, although only $12 \%$ of all patients made use of it. In all four groups, payments for alternative medicines did not exceed $2 \%$ of total direct costs.

Consultations with healthcare workers accounted for $21 \%$ of total direct costs in the total RA population; mean costs per patient were estimated to be $€ 1448$ (1433) in patients with disease duration $<2$ years and $€ 1262$ (1443) in patients with longstanding RA (>10 years). For all 615 patients, contacts with individual healthcare workers, grouped according to distinct disease duration, are presented in table 3. The following healthcare workers were most frequently contacted per 3 months; rheumatologists 1.4 (1.3), general practitioners 0.7 (1.8), physiotherapists 2.9 (6.9), and home help $1.8(7.4)$.

\section{High $v$ low costs}

Demographic, clinical, and psychological characteristics of patients having costs greater than group median $v$ those with costs less than group median are shown in table 4 . In the group of patients with a disease duration of less than 2 years, patients with high costs had significantly worse mobility and more anxiety. In this group, the percentage of patients with low educational level was significantly lower. Within each of the three subsequent disease duration groups the following clinical variables were significantly higher (worse) in patients who had annual costs above group median: ESR, Thompson joint score, functional disability, and QoL. In addition, for disease duration of 2-6 or 6-10 years, early morning stiffness, VAS general wellbeing, VAS pain, and several items on the IRGL questionnaire were significantly worse in patients having high costs compared with those having low costs. Patients having high costs in the 6-10 year disease duration group had had RA for a significantly longer time $(p<0.0001)$. The results of 

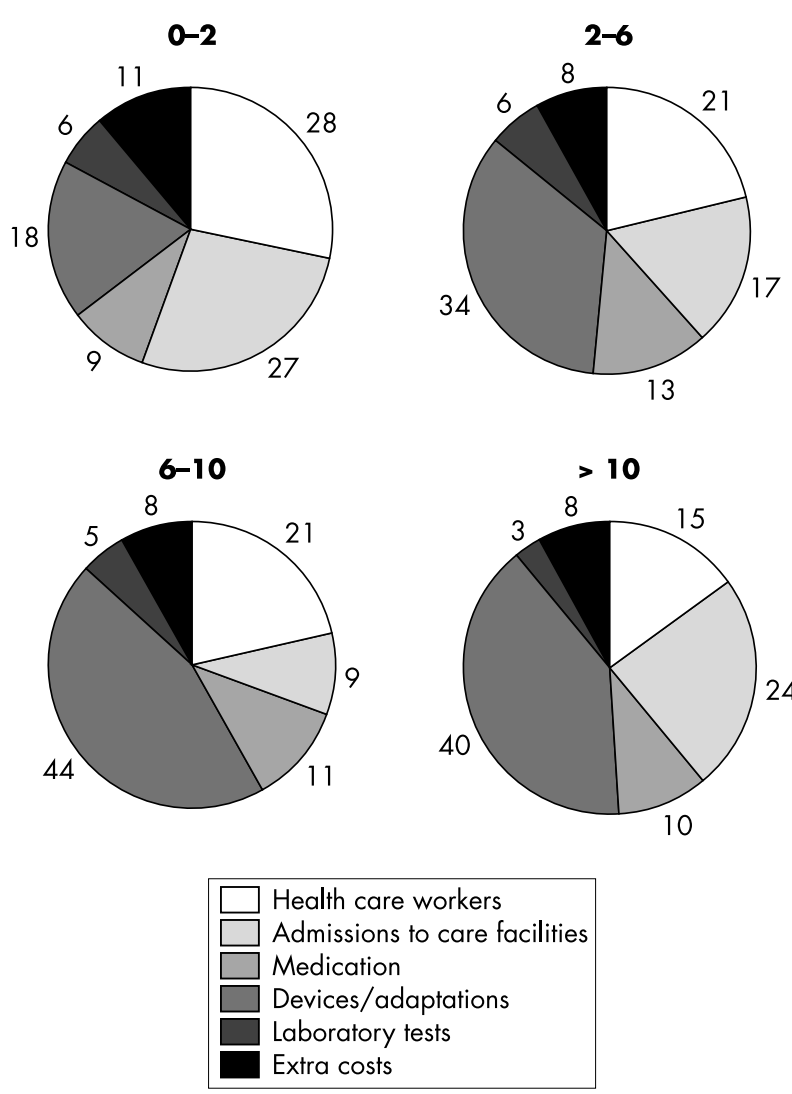

Figure 1 Percentage distribution of total direct costs in the four patient groups with increasing disease duration. Distribution of costs for alternative therapies is not shown because it did not exceed $2 \%$ in any of the four groups.

the multivariate regression analyses are shown in table 5. Among the three groups with a disease duration of more than 2 years, functional disability was the most pronounced variable associated with high costs after adjusting for sociodemographic, clinical, and psychological variables.

\section{Prognostic factors}

Rheumatoid factor positivity at time of diagnosis and less improvement on functional disability after therapy appeared to be the only predictors of long term high costs among a subgroup of 347 patients having complete baseline and first year data (final model, $\mathrm{R}^{2}=0.06$ ).

\section{DISCUSSION}

In this study we compared estimated total direct costs and distribution of different cost categories costs between four disease duration groups of patients with RA ( 0 to $\leqslant 2,2$ to $\leqslant 6,6$ to $<10$, and 10 years). Costs were high for the group of patients with a disease duration of $<2$ years, were slightly less during the subsequent years, but were high again in the group of patients with a disease duration of $>10$ years. A significant difference in annual direct costs between the four groups was found in our study. Mean annual direct costs of all patients were estimated to be $€ 5058$ (equivalent to 5391 in 1999 US dollars). This estimation is quite similar to that found in other COI studies. In a review article, ${ }^{2}$ pooled mean direct costs of several studies were estimated to be $\$ 5720$ (1996 US dollars) per year.

We observed a shift in percentage contribution of various cost categories to total costs across the four groups with distinct disease duration. Although a significant difference in direct costs was found between the four groups with increasing disease duration, the results do not necessarily indicate a certain trend of costs over the course of the disease because the study was done cross sectionally and because recruitment of patients differed among each group. The group of patients with a disease duration $>10$ years contained more women and patients were younger at disease onset. To determine whether a possible trend exists, it is preferable to compare data on costs over time in one RA population-that is, longitudinally. We were able to do this because a subgroup of patients $(n=248)$ of the current study had also filled out a questionnaire on economic evaluation in 1996. ${ }^{5}$ We compared cost data only on 103 patients who had a disease duration of less than 2 years in the 1996 study, because in the present study we found a decrease in costs after that time. However, it must be stressed that in 1996 no guidelines for economic COI studies were available and no

Table 3 Number of consultations with healthcare workers in the preceding 3 months and annual costs per patient shown for four groups of patients with increasing disease duration and for the total study group

\begin{tabular}{|c|c|c|c|c|c|c|c|c|c|c|}
\hline \multirow[b]{3}{*}{ Healthcare worker } & \multicolumn{8}{|c|}{ Disease duration, years } & & \\
\hline & \multicolumn{2}{|c|}{0 to $\leqslant 2(n=96)$} & \multicolumn{2}{|c|}{2 to $\leqslant 6(n=261)$} & \multicolumn{2}{|c|}{6 to $\leqslant 10(n=152)$} & \multicolumn{2}{|c|}{$>10(n=106)$} & \multicolumn{2}{|c|}{ All $(n=615)$} \\
\hline & $\begin{array}{l}\text { Contacts/ } \\
3 \text { months }\end{array}$ & Costs/year & $\begin{array}{l}\text { Contacts/ } \\
3 \text { months }\end{array}$ & $\begin{array}{l}\text { Costs/ } \\
\text { year }\end{array}$ & $\begin{array}{l}\text { Contacts/ } \\
3 \text { months }\end{array}$ & Costs/year & $\begin{array}{l}\text { Contacts/ } \\
3 \text { months }\end{array}$ & Costs/year & $\begin{array}{l}\text { Contacts/ } \\
3 \text { months }\end{array}$ & Costs/year \\
\hline Rheumatologists & $2.4(1.9)$ & $515(364)$ & $1.2(1.1)$ & 221 (193) & $1.2(1.3)$ & $239(260)$ & $1.5(0.9)$ & $318(225)$ & $1.4(1.3)$ & 288 (269) \\
\hline Rheumatology nurse & $1.5(1.8)$ & $141(164)$ & $0.4(1.1)$ & 35 (99) & $0.3(1.2)$ & 30 (111) & $0.2(0.9)$ & $21(82)$ & $0.5(1.3)$ & 48 (119) \\
\hline General practitioner & $0.5(1.1)$ & $36(77)$ & $0.5(1.6)$ & 35 (106) & $0.9(2.4)$ & 60 (159) & $1.0(1.9)$ & 65 (127) & $0.7(1.8)$ & $46(122)$ \\
\hline District nurse & $0.3(2.4)$ & 43 (305) & $0.5(5.8)$ & 69 (739) & $1.5(10.6)$ & $192(1,342)$ & $0.5(2.6)$ & 61 (325) & $0.7(6.6)$ & 94 (843) \\
\hline Formal home help & $1.5(4.3)$ & 103 (303) & $1.1(4.2)$ & 79 (296) & $1.7(8.6)$ & $123(607)$ & $4.0(12.3)$ & $281(868)$ & $1.8(7.4)$ & $129(525)$ \\
\hline $\begin{array}{l}\text { Therapy } \\
\text { Physiotherapy }\end{array}$ & $4.0(8.1)$ & $292(588)$ & $2.6(6.3)$ & $190(454)$ & $2.6(7.1)$ & 189 (512) & $3.2(7.1)$ & $231(520)$ & 2.9 (6.9) & $213(503)$ \\
\hline Hydrotherapy & $0.5(2.1)$ & $32(150)$ & $0.6(2.6)$ & 43 (187) & $0.3(2.4)$ & 21 (171) & $0.7(2.7)$ & 51 (189) & $0.5(2.5)$ & $38(178)$ \\
\hline Exercise therapy & $0.4(2.3)$ & 27 (165) & $0.6(3.3)$ & $44(232)$ & $0.3(2.5)$ & $24(180)$ & $0.6(3.3)$ & $45(235)$ & $0.5(3.0)$ & $37(211)$ \\
\hline Occupational therapist & $0.5(2.1)$ & 38 (151) & $0.1(0.4)$ & $4(26)$ & $0.1(1.1)$ & $10(79)$ & $0.5(2.8)$ & $35(200)$ & $0.2(1.6)$ & $16(112)$ \\
\hline Social worker & $0.1(0.8)$ & 24 (123) & $0.1(0.4)$ & $8(66)$ & $0.1(1.1)$ & 20 (179) & $0.0(0.2)$ & $5(35)$ & $0.1(0.7)$ & $13(111)$ \\
\hline Psychologists & $0.1(0.6)$ & $10(100)$ & $0.0(0.2)$ & $3(40)$ & $0.0(0.4)$ & $5(66)$ & $0(0)$ & $0(0)$ & $0.0(0.4)$ & $4(58)$ \\
\hline Rehabilitation doctor & $0.1(0.4)$ & $14(58)$ & $0.0(0.1)$ & $3(22)$ & $0.0(0.1)$ & $1(13)$ & $0.0(0.2)$ & $5(35)$ & $0.0(0.2)$ & 5 (32) \\
\hline Medical officer & $0.4(0.9)$ & 57 (153) & $0.0(0.2)$ & $5(35)$ & $0.0(0.3)$ & $4(53)$ & $0(0)$ & $0(0)$ & $0.1(0.4)$ & $12(72)$ \\
\hline Personnel officer & $0.1(0.5)$ & $20(76)$ & $0.0(0.4)$ & $6(69)$ & $0.0(2.0)$ & $0(3.3)$ & $0.0(0.2)$ & $3(28)$ & $0.0(0.3)$ & $6(55)$ \\
\hline Pastor & $0.2(1.1)$ & $26(176)$ & $0.0(0.2)$ & $3(34)$ & $0.0(0.3)$ & $4(43)$ & $0.2(0.7)$ & 25 (111) & $0.1(0.5)$ & 10 (89) \\
\hline Other & $0.3(1.3)$ & 71 (252) & $0.4(2.0)$ & 77 (390) & $0.4(1.7)$ & 79 (383) & 0.5 (1.5) & 116 (405) & $0.4(1.8)$ & 83 (372) \\
\hline
\end{tabular}


Table 4 Demographic, clinical, and psychological characteristics, assessed in the year of cost evaluation, of patients with costs less than group median $v$ patients with costs greater than group median, by increasing disease duration

\begin{tabular}{|c|c|c|c|c|c|c|c|c|}
\hline \multirow[b]{3}{*}{$\begin{array}{l}\text { Division by median } \\
\text { direct costs }\end{array}$} & \multicolumn{8}{|c|}{ Disease duration, years } \\
\hline & \multicolumn{2}{|l|}{0 to $\leqslant 2$} & \multicolumn{2}{|l|}{2 to $\leqslant 6$} & \multicolumn{2}{|l|}{6 to $\leqslant 10$} & \multicolumn{2}{|l|}{$>10$} \\
\hline & $\begin{array}{l}\text { Low cost } \\
<2923\end{array}$ & $\begin{array}{l}\text { High cost } \\
\geqslant 2923\end{array}$ & $\begin{array}{l}\text { Low cost } \\
<1968\end{array}$ & $\begin{array}{l}\text { High cost } \\
\geqslant 1968\end{array}$ & $\begin{array}{l}\text { Low cost } \\
<1952\end{array}$ & $\begin{array}{l}\text { High cost } \\
\geqslant 1952\end{array}$ & $\begin{array}{l}\text { Low cost } \\
<3778\end{array}$ & $\begin{array}{l}\text { High cost } \\
\geqslant 3778\end{array}$ \\
\hline Sex, female $(n=615) \S$ & 33 (69) & 37 (77) & 94 (72) & $98(75)$ & $48(63)$ & $54(71)$ & $38(72)^{*}$ & $47(89)$ \\
\hline $\begin{array}{l}\text { Age in years }(n=615) \ddagger \\
\text { Education }(n=603) \S\end{array}$ & $57(14)$ & $51(15)$ & $60(14)$ & $59(14)$ & $63(53-72)$ & $65(55-72)$ & $62(13)$ & $61(12)$ \\
\hline \multicolumn{8}{|l|}{ Education $(n=603) \S$} & \\
\hline $\begin{array}{l}\text { Low } \\
\text { High }\end{array}$ & $\begin{array}{c}4(6) \\
3(6)\end{array}$ & $\begin{array}{l}38(79)^{*} \\
10(21)\end{array}$ & $111(87)$ & $\begin{array}{l}105(84) \\
20(16)\end{array}$ & $\begin{array}{r}67(89) \\
8(11)\end{array}$ & $\begin{aligned} 68(90) \\
8(11)\end{aligned}$ & $\begin{array}{c}50(94) \\
3(6)\end{array}$ & $\begin{array}{c}47(92) \\
4(8)\end{array}$ \\
\hline Disease duration in years & $0.8(0.5-1.2)$ & $0.7(0.4-1.3)$ & $4.0(2.8-5.1)$ & $4.0(3.1-5.2)$ & $7.2(6.6-8.1)$ & $8.2(7.1-9.0)^{*}$ & 17 (13-23) & $16(13-22)$ \\
\hline $\begin{array}{l}\text { VAS disease activity } \\
(\mathrm{n}=594)+\end{array}$ & $75(50-88)$ & $68(42-86)$ & $75(53-90)$ & $51(32-73)^{*}$ & $67(20)$ & $48(24)^{*}$ & $53(24)$ & $47(20)$ \\
\hline ESR $(n=599) \dagger$ & $17(10-31)$ & $22(12-47)$ & $11(6-21)$ & $15(8-26)^{*}$ & $14(7-26)$ & $19(10-34)^{*}$ & $21(14-38)$ & $33(21-50)^{*}$ \\
\hline Morning stiffness $(n=608) \dagger$ & $15(0-60)$ & $1(0-45)$ & $0(0-20)$ & $15(0-60)^{*}$ & $10(0-30)$ & $15(0-60)^{*}$ & $30(6-60)$ & $45(8-90)$ \\
\hline Joint score $(n=607) \dagger$ & $11(0-74)$ & $22(0-128)$ & $0(0-32)$ & $17(0-73)^{*}$ & $0(0-17)$ & $27(0-116)^{*}$ & $5(0-64)$ & $64(22-119)^{*}$ \\
\hline $\begin{array}{l}\text { VAS general wellbeing } \\
(n=605) \dagger\end{array}$ & $24(2-52)$ & $43(2-60)$ & $15(2-43)$ & $37(21-55)^{*}$ & $22(2-35)$ & $46(20-57)^{*}$ & $40(27)$ & $50(26)$ \\
\hline VAS pain $(n=605) \dagger$ & $14(2-32)$ & $17(1-50)$ & $4(0-22)$ & $24(8-46)^{*}$ & $7(1-20)$ & $26(8-56)^{*}$ & $33(5-59)$ & $45(16-58)$ \\
\hline $\begin{array}{l}\text { Functional disability } \\
(\mathrm{n}=576) \pm\end{array}$ & $1.0(0.70)$ & $1.2(0.8)$ & $0.6(0.1-1.1)$ & $1.4(1.0-1.9)^{*}$ & * $0.8(0.6)$ & $1.6(0.7)^{*}$ & $1.2(0.7)$ & $1.9(0.7)^{*}$ \\
\hline $\begin{array}{l}\text { Radiological damage } \\
(n=480) \dagger\end{array}$ & $4(0-10)$ & $4(0-7)$ & $17(7-40)$ & $21(9-53)$ & $27(10-63)$ & $43(22-100)^{*}$ & NA & NA \\
\hline $\begin{array}{l}\text { Rheumatoid factor } \\
\text { positive }(n=406) \S\end{array}$ & 31 (74) & $25(54)$ & $69(60)$ & $55(56)$ & $38(62)$ & 46 (78) & NA & NA \\
\hline Qol $(n=581)$ & $0.7(0.6-0.8)$ & $0.7(0.5-0.8)$ & $0.8(0.7-0.8)$ & $0.6(0.5-0.7)^{*}$ & * $0.8(0.7-0.9)$ & $0.6(0.5-0.7)^{*}$ & $0.6(0.5-0.7)$ & $0.6(0.2-0.7)^{*}$ \\
\hline Mobility $(n=464) \ddagger$ & $21(6)$ & $18(6)^{*}$ & $24(19-28)$ & $19(14-24)^{*}$ & $24(18-28)$ & $14(12-22)^{*}$ & NA & NA \\
\hline Self care $(n=466) \dagger$ & $28(21-32)$ & $26(19-29)$ & $30(24-32)$ & $26(20-30)^{*}$ & $30(25-32)$ & $21(15-27)^{*}$ & NA & NA \\
\hline Pain $(n=467) \dagger$ & $16(13-21)$ & $18(12-22)$ & $11(8-16)$ & $15(12-19)^{*}$ & $12(9-15)$ & $16(12-21)^{*}$ & NA & NA \\
\hline $\begin{array}{l}\text { Depressed mood } \\
(\mathrm{n}=458) \dagger\end{array}$ & $4(2-6)$ & $5(2-8)$ & $1(0-5)$ & $3(0-6)^{*}$ & $0(0-3)$ & $3(1-7)^{*}$ & NA & NA \\
\hline $\begin{array}{l}\text { Cheerful mood } \\
(n=458) \ddagger\end{array}$ & $10(5)$ & $10(5)$ & 12 (9-14) & $11(7-13)$ & $12(10-16)$ & $10(6-14)^{*}$ & NA & NA \\
\hline Anxiety $(n=466) \dagger$ & $17(14-23)$ & $21(16-26)^{*}$ & $17(14-21)$ & $19(15-24)^{*}$ & 15 (13-19) & $19(16-26)^{*}$ & NA & NA \\
\hline $\begin{array}{l}\text { Mann Whitney U test for no } \\
\text { *Significantly different betwe } \\
\text { Values are median }\left(Q_{0.25} \text {. }\right. \\
\text { In column } 1 \text {, total number of } \\
\text { Range scales of IRGL questio } \\
\text { cheerful mood (O-24= best s } \\
\text { NA, no data available. }\end{array}$ & $\begin{array}{l}\text { f patients anal } \\
\text { nnaire: mobil } \\
\text { score), and an }\end{array}$ & $\begin{array}{l}\text { ed for each vc } \\
(7-28=\text { best } \\
\text { ety }(10-40=v\end{array}$ & $\begin{array}{l}\text { ore), self care ( } \\
\text { rst score). }\end{array}$ & est were used for & pain $16-25=$ & prst score), de & ssed mood (0-24 & 4 = worst score), \\
\hline
\end{tabular}

consensus was reached as to which sources to use to value medical utilisation. For the present study, we were able to apply the Dutch guidelines for economic evaluation, such as costs of hospitalisation and costs of visits to healthcare workers. Thus, the comparison of costs between the two studies must be interpreted carefully because costs were not always derived from similar sources. Costs estimated in 1996
Dutch guilders were converted to 1999 estimates in euros using the Dutch consumer price indices for medical care provided by the Dutch Central Bureau of Statistics. ${ }^{18}$ Total direct costs were $€ 6171$ in the 1996 study and $€ 4798$ in the present study. For each category separately, the costs in euros for the 1996 and the present study, respectively, were: (a) consultations with healthcare workers (€1084 $v € 797)$;

Table 5 Results of multiple logistic regression analyses of high costs $v$ low costs for each of the four different disease duration groups

\begin{tabular}{llrrlll}
\hline $\begin{array}{l}\text { Disease duration, } \\
\text { years }\end{array}$ & Associated variable & Estimate $(\boldsymbol{\beta})$ & SE $(\boldsymbol{\beta})$ & $\mathbf{P}$ & OR & $95 \% \mathrm{Cl}$ \\
\hline 0 to $\leqslant 2(\mathrm{n}=59)$ & Age & -0.094 & 0.039 & 0.016 & 0.910 & 0.843 to 0.982 \\
& VAS disease activity & 0.060 & 0.029 & 0.036 & 1.062 & 1.004 to 1.124 \\
& Education $<12$ years & -3.365 & 1.506 & 0.026 & 0.035 & 0.002 to 0.662 \\
& ESR & 0.117 & 0.039 & 0.003 & 1.124 & 1.040 to 1.214 \\
& RF positive & -5.095 & 1.565 & 0.001 & 0.006 & 0.000 to 0.132 \\
& Anxiety & 0.394 & 0.142 & 0.055 & 1.483 & 1.123 to 1.959 \\
& Constant & -3.320 & 3.491 & 0.342 & & \\
2 to $\leqslant 6(n=165)$ & Education $<12$ years & -1.548 & 0.600 & 0.010 & 0.213 & 0.066 to 0.689 \\
& HAQ & 1.917 & 0.382 & 0.000 & 6.799 & 3.218 to 14.365 \\
& VAS general wellbeing & 0.028 & 0.009 & 0.032 & 1.028 & 1.009 to 1.047 \\
6 to $\leqslant 10(n=90)$ & Constant & -1.500 & 0.546 & 0.006 & & \\
& HAQ & 2.087 & 0.444 & 0.000 & 8.060 & 3.38 to 19.226 \\
& Constant & -2.329 & 0.551 & 0.000 & & \\
& HAQ $(n=84)$ & 1.372 & 0.375 & 0.000 & 3.941 & 1.890 to 8.220 \\
& Constant & -2.105 & 0.650 & 0.001 & &
\end{tabular}

Number of patients with complete demographic, clinical, and psychological data is shown in parentheses. $\mathrm{OR}$, odds ratio, $95 \% \mathrm{Cl}, 95$ confidence interval. 
(b) admissions to healthcare facilities (€1200 $v € 1139)$; (c) medication (€610 v €602); (d) laboratory tests (€207 $v € 223) ;(e)$ adaptations and devices $(€ 2220 v € 1535)$; $(f)$ alternative medicines (€79 $v € 45)$; and $(g)$ extra costs (€769v $€ 459)$. In concordance with results presented in this study, direct costs decreased after 2 years in the group of patients evaluated in 1996.

Comparison of percentages contribution of different cost categories observed in our study with those estimated in other COI studies is difficult, because number and/or kind of categories and methods used to estimate costs are often different. It is, therefore, also interesting to compare utilisation rates in addition to costs and percentages of total direct costs. The average number of 5.7 visits per year to rheumatologist found in our study was quite similar to that seen in previous studies, in which annual visits to rheumatologists averaged between 3.4 in a managed care setting, ${ }^{19}$ and 3.9-10.5 in other clinical settings..$^{42021}$ In the group of patients with a disease duration of less than 2 years, rheumatologists and rheumatology nurses were consulted more frequently than in the other three disease duration groups. An explanation might be that patients in the early RA duration group were part of the second inception cohort, and consultations were therefore more frequent than usual (see Patients and methods). An average of 1.6 consultations/ patient/year with employers' medical officers during the first 2 years after disease onset seems high; however, in the Netherlands persons who are on sick leave for long periods of time are obliged to contact their employer's medical officer. Patients with recent onset of RA are often on sick leave owing to high disease activity, and may become work disabled even in the first years after disease onset. ${ }^{22} 23$

In this study, we asked patients to report the number of days they were hospitalised in the previous year, and the number and type of any surgical operations undergone, if any. Because admissions to hospitals most often account for high costs, we examined the medical records of these patients to verify whether the number of days and operations were reported correctly, and found that they were. The annual average length of hospitalisation ( 13 days) of these patients in our study is comparable to that found in previous studies, ranging from 8 to 14 days. ${ }^{70} 24-26$.

In the group of patients with a disease duration of more than 2 years, total direct costs were mainly costs due to purchase of devices and/or adaptations. The high costs of these can possibly be explained by the severity of the disease of these patients with RA of longer than 2 years' duration, reflected by increased functional disability. In the Netherlands, some of these costs are reimbursed by health insurance companies or special foundations such as the Dutch Arthritis Association. In the current study, major adaptations were mainly reimbursed by the local social security system for disabled persons. The rates for reimbursement and kind of adaptations considered for reimbursement may differ between cities. Devices were especially (partly) reimbursed by either public or private health insurance companies.

Costs for medication may have been underestimated because we asked explicitly for RA related medication, not for example, supplementary gastrointestinal drugs to prevent NSAID induced symptoms. Although some patients reported that they used gastrointestinal related drugs, others may not have done. The costs of these drugs might well attribute to high costs for RA patients, ${ }^{52}$ thus if we had taken these drugs fully into account they might have increased the estimated costs for medication use. Furthermore, owing to increased use of more expensive medication including anti-TNF- $\alpha$ and other biological agents, future medication costs will probably rise considerably.

Interestingly, alternative medicines only accounted for less than $2 \%$ of total direct costs. This percentage is similar to that observed in a previous study including a subgroup of the present study population. ${ }^{5}$ Nevertheless, patients who had a disease duration of less than 2 years spent on average $€ 103$ on alternative medicines. This amount decreased with increasing disease duration, possibly indicating that patients try different treatment regimens early after diagnosis, and consequently seem to lose faith in alternative medicines during the following years.

In the present study, clinical, demographic, functional, and/or psychological variables were also studied for a possible relation to high costs in the same year as costs were estimated. In the first 2 years of disease, only two items of the IRGL questionnaire were related to high costs. After 2 years, ESR, Thompson joint score, and functional disability were significantly worse for patients with high costs. In addition, other additional variables were also significantly worse for the high cost group in the two middle disease duration groups ( 2 to 6 and 6 to 10 years). In other studies it has been found that total direct costs increase from $€ 1643$ for patients in functional class I to $€ 5696$ for patients in functional class IV, ${ }^{20}$ and that functional disability is also the most important determinant of RA related health expenditures..$^{5-7} 27$ Furthermore, rheumatoid factor positivity at baseline and less improvement on functional disability after therapy over the first year predicted long term high costs in our study. Overall baseline predictors of high costs as those found in our study must be interpreted with caution, because the final model only explained $6 \%$ of the total variance. In addition, only patients included in the first inception cohort of the Utrecht Rheumatoid Arthritis Cohort Study group (disease duration 2-10 years) were included in the regression analysis.

\section{CONCLUSION}

Mean annual direct costs of 615 Dutch RA patients with a mean disease duration of 7 years were estimated to be $€ 5058$. Annual direct costs differed between the four distinct disease duration groups. Costs were high for patients with a disease duration of less than 2 years, were slightly less thereafter, and were high again among patients with a disease duration of more than 10 years. In addition, percentage distribution of total costs for different cost categories changed across the four disease duration groups. Functional disability was associated with high costs and was a predictor of high costs. Thus, a rapid improvement of functional disability (that is, reduction of disease activity and prevention of radiological damage) might reduce the financial burden on individual RA patients, health services, and society. The concept of early aggressive treatment of RA is supported by these cost of illness data.

\section{ACKNOWLEDGEMENTS}

The authors wish to thank all participating rheumatologists and research nurses of the Utrecht Rheumatoid Arthritis Cohort Study group (SRU) for their contribution to the investigation described in this paper. This study was financially supported by a grant from the Dutch Arthritis Association.

\section{Authors' affiliations}

S M M Verstappen, J W G Jacobs, A A Kruize, J W J Bïlsma, University Medical Center Utrecht, Utrecht, The Netherlands H Verkleii, National Institute of Public Health and the Environment, Bilthoven, The Netherlands

E Buskens, Julius Centre for Health Sciences and Primary Care, UMC Utrecht, the Netherlands

A H M Heurkens, Meander Medical Center, Amersfoort, The Netherlands

M J van der Veen, Hospital Sint Jansdal, Harderwijk, The Netherlands 


\section{APPENDIX}

Unit prices for contacts with health professionals, admissions in care facilities and travel expenses.

Costs $(€)$ per visit for consultations with health professionals, daily costs for admissions to care facilities, and costs per kilometre for travel expenses.

\begin{tabular}{|c|c|}
\hline & Cost \\
\hline \multicolumn{2}{|l|}{ Consultations } \\
\hline \multicolumn{2}{|l|}{ Rheumatologists } \\
\hline University hospital & 72.60 \\
\hline General hospital & 40.84 \\
\hline Rheumatology nurse & 23.14 \\
\hline General practitioner & 16.79 \\
\hline District nurse & 31.76 \\
\hline Home help & 18.15 \\
\hline \multicolumn{2}{|l|}{ Therapy } \\
\hline Physiotherapy & 18.15 \\
\hline Hydrotherapy & 18.15 \\
\hline Exercise therapy & 18.15 \\
\hline Occupational therapist & 18.15 \\
\hline Social worker & 40.84 \\
\hline Psychologists & 40.84 \\
\hline Rehabilitation doctor & 40.84 \\
\hline Medical officer & 40.84 \\
\hline Personnel officer & 40.84 \\
\hline Pastor & 40.84 \\
\hline \multicolumn{2}{|l|}{ Other specialist } \\
\hline University hospital & 72.60 \\
\hline General hospital & 40.84 \\
\hline \multicolumn{2}{|l|}{ Admission to care facility } \\
\hline \multicolumn{2}{|l|}{ Hospital } \\
\hline University hospital & 331.71 \\
\hline General hospital & 235.97 \\
\hline Rehabilitation centre & 284.97 \\
\hline \multicolumn{2}{|l|}{ Travel expenses } \\
\hline Own car & 0.11 \\
\hline Public transport (bus, train) & 0.11 \\
\hline Taxi & 1.35 \\
\hline
\end{tabular}

\section{REFERENCES}

1 Lubeck DP. The economic impact of arthritis. Arthritis Care Res 1995:8:304-10.

2 Cooper NJ. Economic burden of rheumatoid arthritis: a systematic review. Rheumatology (Oxford) 2000;39:28-33.

3 Clarke AE, Levinton C, Joseph L, et al. Predicting the short term direct medical costs incurred by patients with rheumatoid arthritis. J Rheumatol 1999:26:1068-75.

4 Yelin E, Wanke LA. An assessment of the annual and long-term direct costs of rheumatoid arthritis: the impact of poor function and functional decline. Arthritis Rheum 1999:42:1209-18.
5 van Jaarsveld $\mathrm{CH}$, Jacobs JW, Schrijvers AJ, et al. Direct cost of rheumatoid arthritis during the first six years: a cost-of-illness study. $\mathrm{Br} J$ Rheumatol 1998; 37:837-47.

6 Liang MH, Larson M, Thompson $M$, et al. Costs and outcomes in rheumatoid arthritis and osteoarthritis. Arthritis Rheum 1984;27:522-9.

7 Lubeck DP, Spitz PW, Fries JF, et al. A multicenter study of annual health service utilization and costs in rheumatoid arthritis. Arthritis Rheum 1986:29:488-93.

8 van Jaarsveld CH, Jacobs JW, van der Veen MJ, et al. Aggressive treatment in early rheumatoid arthritis: a randomised controlled trial. On behalf of the Rheumatic Research Foundation Utrecht, The Netherlands. Ann Rheum Dis 2000;59:468-77.

9 van der Heide A, Jacobs JW, Bijlsma JW, et al. The effectiveness of early treatment with "second-line" antirheumatic drugs. A randomized, controlled trial. Ann Intern Med 1996;124:699-707.

10 Arnett FC, Edworthy SM, Bloch DA, et al. The American Rheumatism Association 1987 revised criteria for the classification of rheumatoid arthritis. Arthritis Rheum 1988;31:315-24

11 The EuroQol group. The EuroQol: A new facility for measurement of health related quality of life. Health Policy 1990;16:199-208.

12 Merkesdal S, Ruof J, Huelsemann JL, et al. Development of a matrix of cost domains in economic evaluation of rheumatoid arthritis. J Rheumatol 2001;28:657-61.

13 Oostenbrink JB, Koopmanschap MA, Rutten FFH. Guideline for cost-of-illness study; Methods and guideline-rates for economic evaluations in health care. Guideline for cost-of-illness study. Amstelveen, The Netherlands: College voor Zorgverzekeringen, 2000

14 Dutch College for Rates in Health Care (CTG) (College tarieven gezondheidszorg). Handbook, 2002. Utrecht, The Netherlands.

15 Huiskes CJAE, Kraaimaat, Biilsma JW. Development of a self-report questionnaire to assess the impact of rheumatic diseases on health and lifestyle. J Rehabil Sci 1990;3:65-70.

16 Pham B, Cranney A, Boers M, et al. Validity of area-under-the-curve analysis to summarize effect in rheumatoid arthritis clinical trials. J Rheumatol 1999;26:712-16.

17 Matthews JN, Altman DG, Campbell MJ, Royston P. Analysis of serial measurements in medical research. BMJ 1990;300:230-5.

18 The Dutch Bureau of Statistics (Centraal Bureau voor de Statistiek). Voorburg, The Netherlands, 1999.

19 Lanes SF, Lanza LL, Radensky PW, et al. Resource utilization and cost of care for rheumatoid arthritis and osteoarthritis in a managed care setting: the importance of drug and surgery costs. Arthritis Rheum 1997;40:1475-81.

20 Leardini G, Salaffi F, Montanelli R, et al. A multicenter cost-of-illness study on rheumatoid arthritis in Italy. Clin Exp Rheumatol 2002;20:505-15.

21 Ruof J, Hulsemann JL, Mittendorf T, et al. Costs of rheumatoid arthritis in Germany: a micro-costing approach based on healthcare payer's data sources. Ann Rheum Dis 2003:62:544-9.

22 van Jaarsveld $\mathrm{CH}$, Jacobs JW, Schriivers $\mathrm{AJ}$, et al. Effects of rheumatoid arthritis on employment and social participation during the first years of disease in The Netherlands. Br J Rheumatol 1998;37:848-53.

23 Doeglas D, Suurmeijer T, Krol B, et al. Work disability in early rheumatoid arthritis. Ann Rheum Dis 1995:54:455-60.

24 Jacobs J, Keyserling JA, Britton M, et al. The total cost of care and the use of pharmaceuticals in the management of rheumatoid arthritis: the Medi-Cal program. J Clin Epidemiol 1988;41:215-23.

25 Spitz PW. The medical, personal, and social costs of rheumatoid arthritis. Nurs Clin North Am 1984;19:575-82.

26 Jacobi CE, Triemstra M, Rupp I, et al. Health care utilization among rheumatoid arthritis patients referred to a rheumatology center: unequal needs, unequal care? Arthritis Rheum 2001;45:324-30.

27 Lajas C, Abasolo L, Bellajdel B, et al. Costs and predictors of costs in rheumatoid arthritis: A prevalence based study. Arthritis Rheum 2003;49:64-70. 